\title{
Sustained-release progesterone nanosuspension following intramuscular injection in ovariectomized rats
}

This article was published in the following Dove Press journal:

International Journal of Nanomedicine

9 November 2010

Number of times this article has been viewed

\author{
Heba F Salem \\ Faculty of Pharmacy, Beni-Suef \\ University, Beni-Suef, Egypt
}

Correspondence: Heba F Salem Faculty of Pharmacy, Beni-Suef University, El-Shahid/Shehata Ahmed Hijaz St, Beni-Suef, Egypt

Tel +20 I0I 94438 I

Email heba_salem2004@yahoo.co.uk
Abstract: The production of an intramuscular (IM) injection of natural progesterone would provide a safer solution than using semi synthetic progesterone. However, disadvantages such as low solubility and a short half life prevent the use of natural progesterone. In this study, we formulated a sustained release form of natural progesterone to be given as IM injection. A progesterone nanosuspension (PNS) was first developed and then dispersed in a thermosensitive gel matrix. The selected nanoparticles showed an average particle size of $267 \mathrm{~nm}$ and a zeta potential approaching-41 mV. The in vitro release profile of PNS from the F127 plus methyl cellulose gel followed zero order kinetics and correlated linearly with the weight percentage of gel dissolved, demonstrating that the overall rate of release of PNS is controlled by dissolution of the pluronic F127/methyl cellulose (MC) gel ( $\left.\mathrm{r}^{2}>0.99\right)$. The pharmacokinetic parameters of the PNS $(6 \mathrm{mg} / \mathrm{mL})$ in pluronic F127/MC gel were evaluated in comparison with the control progesterone suspension. After the administration of PNS in F127/MC gel into the rats, a maximum serum concentration of $22.1 \pm 1.9 \mathrm{ng} / \mathrm{mL}$ was reached at a $\mathrm{T}_{\max }$ of $4.05 \pm 0.1 \mathrm{~h}$. The terminal half life was $12.7 \pm 0.8 \mathrm{~h}$. The area under the curve $\mathrm{AUC}_{0-\infty}$ of the injected formula was $452.75 \pm 42.8 \mathrm{ng} \cdot \mathrm{h} / \mathrm{mL}$ and the total mean residence time was $18.57 \pm 1.44 \mathrm{~h}$. The PNS in gel was significantly different from the control in rate and extent at $P<0.001$. The natural progesterone which was nanosized and formulated in a thermosensitive gel significantly sustained the action of natural progesterone so that it could be injected every $36 \mathrm{~h}$ instead of every day. Moreover, this formula is expected to provide a much safer choice than the use of semi-synthetic progesterone.

Keywords: progesterone, nanosuspension, thermosensitive gel, ovariectomized female rats

\section{Introduction}

Since the 1950s, a variety of gynecological conditions have been either corrected or treated using oral synthetic progesterone. However, the androgenic activity inherent in these synthetic compounds minimizes its extensive use in reproductive technology because of the risk of teratogenic effects. Furthermore, the use of synthetic progesterone as a luteal support may partially diminish the estrogenic benefits due to adverse effects on the cardiovascular system and lipoprotein metabolism. ${ }^{1-3}$

Natural progesterone is free of any androgenic activity that might affect lipoprotein metabolism or induce teratogenicity. In addition, it probably has a beneficial effect on blood vessels. ${ }^{4}$ The major problem with natural progesterone is its route of administration since it is a hydrophobic drug which undergoes a first pass effect by the liver when it is given orally. $2,5,6$

An intramuscular (IM) injection of progesterone assures reliable absorption, but it has a low compliance due to the use of oil as a vehicle. Although, it is highly 
successful in achieving high serum levels of progesterone, the daily injection of progesterone for up to 10 weeks (in case of using it as luteal support if pregnancy occurs) leads to pain and local inflammatory actions and may lead to sterile abscesses. ${ }^{6,7}$ Hydrophilic vehicles are preferable to using oil. However, their use as carriers is mainly confined to hydrophilic drugs. Hydrophobic drugs such as progesterone need size reduction and surface modifications for a uniform distribution within hydrophilic vehicles. However, nanonization and surface modifications can both provide a uniform distribution of hydrophobic drugs within hydrophilic gels.

Many drugs are formulated as a nanosuspension, such as cyclosporine, ${ }^{8}$ griseofulvin, ${ }^{9}$ retinoic acid, ${ }^{10}$ albendazole, ${ }^{11}$ amphotericin B, ${ }^{12}$ budesonide, ${ }^{13}$ clofazamine,${ }^{14}$ glucocorticoid drugs, ${ }^{15}$ mitotane, ${ }^{16}$ and nifedipine. ${ }^{17}$

There are two main methods of producing nanosuspensions: the first one is via the solvent precipitation technique, ${ }^{10}$ the other one is via high pressure homogenization. ${ }^{14}$ The precipitation technique is preferred in many situations due to its low cost and high efficiency. The drug is dissolved in an organic solvent and the solution is then mixed with a miscible antisolvent. Water is usually used as an antisolvent in cases where the solubility of a drug is low and the drug precipitates easily..$^{9,10,16}$ The stability of the particles obtained in the nanosuspension is attributed to their uniform particle size and due to the stabilization of their surfaces by amphiphilic surfactants. ${ }^{18}$

The use of hydrophilic matrices (polymers) is a common practice for elongating the release of drugs as they are proven to be safe and effective. Pluronics have been cited in the literature as being used as hydrophilic thermosensitive polymers for sustaining the action of many hydrophilic drugs given by injection, such as interleukin- $2,{ }^{19}$ recombinant human growth hormone, ${ }^{20}$ and deslorelin. ${ }^{21}$

Pluronics are a family of commercially available block copolymers with variable surface properties. Pluronic F127, also known as poloxamer 407, is an ABA block copolymer formed of poly(oxyethylene) units (70\%) referred to as A and poly(oxypropylene) blocks (30\%) referred to as $\mathrm{B},{ }^{22}$ which undergo a thermogelation phenomenon upon increasing temperatures. This phenomenon is responsible for elongating the release of drugs. ${ }^{21}$

The aim of this work was to engineer a sustained-release thermosensitive injection of a progesterone nanosuspension (PNS) stabilized by amphiphilic moieties. The amphiphilic moiety (stearic acid) was used to facilitate the dispersion of the nanosuspension in the hydrophilic matrices. ${ }^{18}$ This formula could later be used as a luteal supporting agent in oocyte retrieval. The second aim of the study was to compare the in vivo performance of the chosen formula with an equivalent dose of natural progesterone powder in ovariectomized female rats.

\section{Materials and methods Materials}

PluronicF127, progesterone powder $\mathrm{C}_{21} \mathrm{H}_{30} \mathrm{O}_{2}$ (4-pregene-3,20dione), stearic acid, methyl cellulose (MC) with a viscosity of 400 centiPoises (cP), hydroxy propyl methyl cellulose (HPMC) with a viscosity of 80-120 cP, phosphate-buffered saline (PBS) tablets containing $\mathrm{NaCl}(0.1 \mathrm{~N})$, and phosphate buffer (0.01 M, pH 7.4) were all purchased from Sigma Aldrich (Cairo, Egypt). Absolute ethanol (95\% v/v) was provided by Thermo Fisher's analytical technologies segment (Thermo Fisher Scientific Inc., Cairo, Egypt). The ELISA kit for progesterone detection was purchased from BioTina GmbH (Hagen, Germany).

\section{Preparation of PNS}

Preparation of the nanoparticles was carried out using the solvent precipitation method with modifications. ${ }^{18}$ In brief, nanoparticles were prepared by the rapid mixing of progesterone (200 mg) with different amounts of stearic acid powder $(5 \%, 10 \%$, and $20 \% \mathrm{w} / \mathrm{w})$ in ethanol $(1 \mathrm{~mL})$. This solution was added to $60 \mathrm{~mL}$ of cold deionized water using syringe dropping under probe sonication (model GM 2200; Bandolin Electronic, Berlin, Germany) at $60 \%$ amplitude for $20 \mathrm{~s}$. The resulting colloid was then frozen at $-20^{\circ} \mathrm{C}$ and freeze dried. A small volume of the colloid $(1 \mathrm{~mL})$ was kept back from lyophilization for the purpose of imaging and particle size measurement.

The yield was calculated using the following equation (Eq. (1)):

$$
\text { Yield }=\text { Mass }_{\text {powder }} / \text { Mass }_{\text {initial }} \times 100
$$

\section{Particle size analysis}

The z-average particle sizes and polydispersity index were determined using the PCS4700 system (Malvern Instruments, Malvern, UK), while the zeta potential of the nanosuspension samples was determined using the Zetasizer 2000 (Malvern Instruments).

\section{Differential scanning calorimetry}

Progesterone powder, stearic acid, or PNS (4 mg) were sealed in the flat-bottomed aluminum pan of the differential scanning calorimetry (DSC) (DSC-50; Shimadzu Corporation, Kyoto, 
Japan). A standard empty pan was inserted along with each pan to account for the heating of pure aluminum. The sample and the blank were continuously purged with nitrogen gas at a flow rate of $25 \mathrm{~mL} / \mathrm{min}$. Data collection was carried out at the temperature range of $20^{\circ} \mathrm{C}$ to $200^{\circ} \mathrm{C}$ and the heating rate was $5^{\circ} \mathrm{C} / \mathrm{min}$. The melting and transition point measurements were performed using the software provided with the device.

\section{Scanning electron microscopy}

The PNS in PBS was mounted onto cupper stubs with doublesided adhesive tape and coated with gold using a Sputter Coater (S150A; Edwards High Vacuum Ltd, Crawley, UK). The sample was examined under a JXA-840 A electron probe microanalyzer (JEOL Ltd., Akishima, Japan).

\section{In vitro release study of the nanosuspensions}

Six milligrams of the post-treated solid residues in the previous section were re-dispersed in $2 \mathrm{~mL}$ of PBS ( $\mathrm{pH} 7.4)$ and then transferred to a dialysis bag (molecular weight cut-off $4 \mathrm{kDa}$ ). These bags were hung in a covered beaker containing the dissolution medium $(60 \mathrm{~mL})$. The dissolution medium was stirred at $200 \mathrm{rpm}$ at room temperature. The drug contents were determined using an ELISA kit (BioTina $\mathrm{GmbH}$ ) at different time intervals. As a comparison, the diffusion profile of the pure drug dispersion was examined through the dialysis bag. The pure drug dispersion was prepared by dispersing an equivalent amount of progesterone powder in $2 \mathrm{~mL}$ of PBS. Each releasing experiment was performed in triplicate. ${ }^{18}$

\section{Preparation of pluronic thermosensitive gel bases}

One milliliter of isotonic PBS (0.1 M, pH7.4) was used in each base preparation. Appropriate amounts of pluronic F127 were used alone or premixed with either $\mathrm{MC}(1 \% \mathrm{w} / \mathrm{v})$ or HPMC $(1 \% \mathrm{w} / \mathrm{v})$ to modify the rate at which the pluronic gels dissolved (Table 1). The final concentrations of pluronic

Table I Composition of different thermosensitive bases. B represents the base number. All bases contain the same amount of progesterone $(6 \mathrm{mg} / \mathrm{mL})$

\begin{tabular}{llll}
\hline The additives & $\begin{array}{l}\text { Pluronic } \\
(\mathbf{I 7 \%} \mathbf{w} / \mathbf{v})\end{array}$ & $\begin{array}{l}\text { Pluronic } \\
\mathbf{( 2 5 \%} \mathbf{w} / \mathbf{v})\end{array}$ & $\begin{array}{l}\text { Pluronic } \\
\mathbf{( 3 0 \%} \mathbf{w} / \mathbf{v})\end{array}$ \\
\hline None & $\mathrm{BI}^{\mathrm{a}}$ & $\mathrm{B} 4$ & $\mathrm{~B} 7$ \\
HPMC $(1 \% \mathrm{w} / \mathrm{v})$ & $\mathrm{B} 2$ & $\mathrm{~B} 5$ & $\mathrm{~B} 8$ \\
$\mathrm{MC}(1 \% \mathrm{w} / \mathrm{v})$ & $\mathrm{B} 3$ & $\mathrm{~B} 6$ & $\mathrm{~B} 9$ \\
\hline
\end{tabular}

F127 were $17 \% \mathrm{w} / \mathrm{v}, 25 \% \mathrm{w} / \mathrm{v}$, and $30 \% \mathrm{w} / \mathrm{v}$, respectively. The weights of the nine bases were kept constant by adding a sufficient amount of buffer. The mixtures were vortexed and kept in the fridge for $24 \mathrm{~h}$ before use. For preparation of the pluronic bases to carry the progesterone nanoparticles, the nanoparticles were first premixed with pluronic F127 with or without the above additives before being mixed with different volumes of PBS to keep the final volume constant in all preparations. The final concentrations of progesterone were $6 \mathrm{mg} / \mathrm{mL}$ in all preparations.

\section{Characterization of the thermosensitive bases}

\section{Gelling point determination and rheological} characterization of the thermosensitive bases

The inverted test-tube method was used to determine the gelling point of the bases. One milliliter of each base, either with or without the nanoparticles, was put in a water bath with temperature increasing from $4-60^{\circ} \mathrm{C}$. The sol-gel transition temperature was assessed. The base is regarded as "gel" if it could not flow down the test tube when it was inverted.

The nine bases were tested for their viscosity in the presence or in the absence of progesterone nanoparticles (6 mg) using a Brookfield viscometer (DV-III programmable Rheometer; Brookfield Engineering LABS, Stoughton, MA). The measurements were carried out over the entire range of speed setting from 1-200 rpm with $60 \mathrm{~s}$ between each successive points with the temperature controlled at $4^{\circ} \mathrm{C}$.

The cumulative percentage weight of dissolved gel (matrix erosion or weight loss)

The nine pluronic bases were placed into a thermostaticallycontrolled water bath (Aditi Associate, Mumbai, India) maintained at $37^{\circ} \mathrm{C}$ for $8 \mathrm{~h}$. The difference in weights of the vials with and without the bases gave the initial weight of the pluronic bases used, while the difference in weight of the pluronic bases at two adjacent points after addition of the buffer represented the amount of dissolved gel.

\section{In vitro release studies of the PNS from the gel}

An in vitro release study of the PNS from the F127 gel was performed using a membrane less dissolution model. ${ }^{21}$ One milliliter of the different pluronic bases alone or with either HPMC or MC was placed into $3 \mathrm{~mL}$ vials. The vials were placed into the shaking water bath, which was maintained at $37^{\circ} \mathrm{C}$. After the drug bases had transformed into a gel form, the PBS solution ( $1 \mathrm{~mL}, \mathrm{pH} 7.4$ ) was carefully layered over 
the surface of the gel. At predetermined time intervals, the entire release medium was removed, the vial was weighed and fresh medium was replaced. The samples were analyzed for progesterone using an ELISA microplate autoreader (Model EL-311; Bio-Tek Vermont, CA) according to the manufacturer's instructions (BioTina $\mathrm{GmbH}$ ).

\section{Preparation of animals}

Twelve adult female Sprague-Dawley rats with an average weight of 250-300 g were provided by the animal house of the National Organization of Drug Control and Research, Egypt. All of the animals were handled humanely according to the Helsinki protocols. Before the experiment, the rats were humanely ovariectomized according to the method of Flores et al. ${ }^{23}$ Briefly, the rats were anesthetized and the lower abdomen was shaved and incised. Both ovaries were removed and then the ovariectomized rats were kept for two weeks after the operations before injecting them with a progesterone base. The doses were calculated according to Paget and Barners ${ }^{24}$ to be equivalent to doses used for humans.

\section{Treatment and blood sampling}

At the time of the experiment, the rats were divided into two groups; each group contained six female rats. The first group was injected with B6 $(1000 \mu \mathrm{L})$ which was composed of progesterone $(6 \mathrm{mg} / \mathrm{mL})$, pluronic $\mathrm{F} 127$ of $25 \% \mathrm{w} / \mathrm{v}$ plus MC $(1 \% \mathrm{w} / \mathrm{v})$. The second set of rats was injected with natural progesterone suspended in PBS $(6 \mathrm{mg} / \mathrm{mL})$. All mixtures were IM injected into the lower limb of the rats. Blood samples $(250 \mu \mathrm{L})$ were drawn at $0,0.25,0.5,0.75,1$, $2,4,6,8,24$, and $36 \mathrm{~h}$ post administration. The plasma was separated and frozen. The plasma progesterone concentration was determined using a BioTek ELISA microplate autoreader (Model EL-311) according to the manufacturer's instructions (BioTina $\mathrm{GmbH}$ ). The mean levels of endogenous progesterone in the investigated rats were assessed at $48 \mathrm{~h}$ before the experiment and found to be $0.36 \pm 0.12 \mathrm{ng} / \mathrm{mL}$. These values were used to correct the level of exogenous progesterone. Therefore, the level of endogenous progesterone of each rat was subtracted from the level of exogenous progesterone at each point on the area under curve to exclude the effect of any small fractions of endogenous progesterone.

\section{Results and discussion}

Natural progesterone is the most important drug used as a luteal support in oocyte retrieval. The importance of natural progesterone arises from its similarity to the progesterone naturally present in high concentrations in the body and therefore does not pose any toxicity problems, unlike synthetic progesterone. ${ }^{25,26}$ Progesterone is not orally active except in high doses and has a very short biological half life, which makes it an ideal candidate for inclusion in a thermosensitive matrix which controls its deposition and sustains its action when given by the IM route of administration. Hydrophobicity, low solubility, and the large particle size of natural progesterone hinder its uniform distribution in hydrophilic thermosensitive polymers. Therefore, size reduction and surface stabilization by stearic acid is thought to provide uniform distribution within the hydrophilic matrix when examined under the microscope and also by eye. ${ }^{18}$

\section{Preparation and characterization of the nanosuspensions}

In this section of the study, sustained-release injections of natural PNS using stearic acid as the surface stabilizer were prepared. Stearic acid has amphiphilic characteristics as it is a solid at room temperature, and is thought to form a thin layer surrounding the drug nanodispersion. The amphiphilic nature of stearic acid makes it act as an interface between the progesterone nanoparticles and the hydrophilic medium. Stearic acid is presumed to be the provider of the negative charges on the surface of the hydrophobic progesterone (Table 2). ${ }^{18}$ All of the nanosuspension formulations showed a macroscopic homogenous appearance, which

Table 2 Physicochemical properties of progesterone nanoparticles

\begin{tabular}{|c|c|c|}
\hline $\begin{array}{l}\text { Concentration } \\
\text { of stearic acid }\end{array}$ & Parameters & Value \pm SD \\
\hline \multirow[t]{4}{*}{ Stearic acid $(5 \% \mathrm{w} / \mathrm{w})$} & Zeta potential $(\mathrm{mV})$ & $-23 \pm 7$ \\
\hline & $\begin{array}{l}\text { Mean particle size } \\
\text { diameter }(\mathrm{nm})\end{array}$ & $680 \pm 60$ \\
\hline & $\begin{array}{l}\text { Polydispersity index } \\
\text { of the NP }\end{array}$ & $0.36 \pm 0.1$ \\
\hline & Yield & $40 \%$ \\
\hline \multirow[t]{4}{*}{ Stearic acid $(10 \% \mathrm{w} / \mathrm{w})$} & Zeta potential (mV) & $-37 \pm 6$ \\
\hline & $\begin{array}{l}\text { Mean particle size } \\
\text { diameter }(\mathrm{nm})\end{array}$ & $290 \pm 20$ \\
\hline & $\begin{array}{l}\text { Polydispersity index } \\
\text { of the NP }\end{array}$ & $0.24 \pm 0.09$ \\
\hline & Yield & $69 \%$ \\
\hline \multirow[t]{4}{*}{ Stearic acid $(20 \% \mathrm{w} / \mathrm{w})$} & Zeta potential (mV) & $-4 \mid \pm 5$ \\
\hline & $\begin{array}{l}\text { Mean particle size } \\
\text { diameter }(\mathrm{nm})\end{array}$ & $267 \pm 10$ \\
\hline & $\begin{array}{l}\text { Polydispersity index } \\
\text { of the NP }\end{array}$ & $0.21 \pm 0.02$ \\
\hline & Yield & $82 \%$ \\
\hline
\end{tabular}

Abbreviation: SD, standard deviation. 
was milky white in color when examined by eye before lyophilization.

The amount of stearic acid added was found to have the main effect on the particle size produced. The particles with the smallest sizes were those produced with highest amount of stearic acid (Table 2). The yield also increased by increasing the concentration of stearic acid used, which may be due to the repulsion occurring between the nanoparticle surfaces and the walls of the glass vessels upon transfer. We presumed that the ratio between progesterone and stearic acid was still the same after lyophilization in each case.

It was also observed that nanoparticle size could be controlled by controlling the operating conditions during the formation of the colloid, such as the volume of the solvent/ antisolvent system (data not shown), because the percentage of the particle precipitation was strongly dependent on the relative solubility of the drug in both phases (solvent/ antisolvent). Other operating conditions were found to have effect on particle size, such as mixing energy and length of the mixing time (data not shown).

Sufficient mixing of these two phases, which was achieved via ultrasonication at low to moderate amplitudes, led to nucleation and growth kinetics and finally to the formation of submicron particle sizes.

Particle size analysis showed the presence of submicron structures with acceptable polydispersity indices (Table 2). The results were in agreement with the electron micrograph results. Scanning electron microscopy showed the formation of spherical and oblate shaped nanoparticles, somewhere below $500 \mathrm{~nm}$ in size. The size distribution was in accordance with other nanosuspension systems described in the literature. ${ }^{18}$ Sickle shaped nanoparticles were also seen and thought to be the aggregation of two or three oblate nanoparticles, all below $1 \mu \mathrm{m}$ in size. The presence of these aggregates may have been the reason for the relatively high polydispersity indices (Figure 1).

DSC thermographs were used to investigate the presence of chemical interactions between progesterone and stearic acid which may affect the therapeutic effect of progesterone. Both progesterone and stearic acid exhibited sharp endothermic peaks when they underwent a melting phenomenon upon heating (Figure 2). The results showed a lack of interaction between the drug and stearic acid, which suggested the formation of physical mixture in the case of the nanosuspension. It was also found that the enthalpy of the nanoparticles was
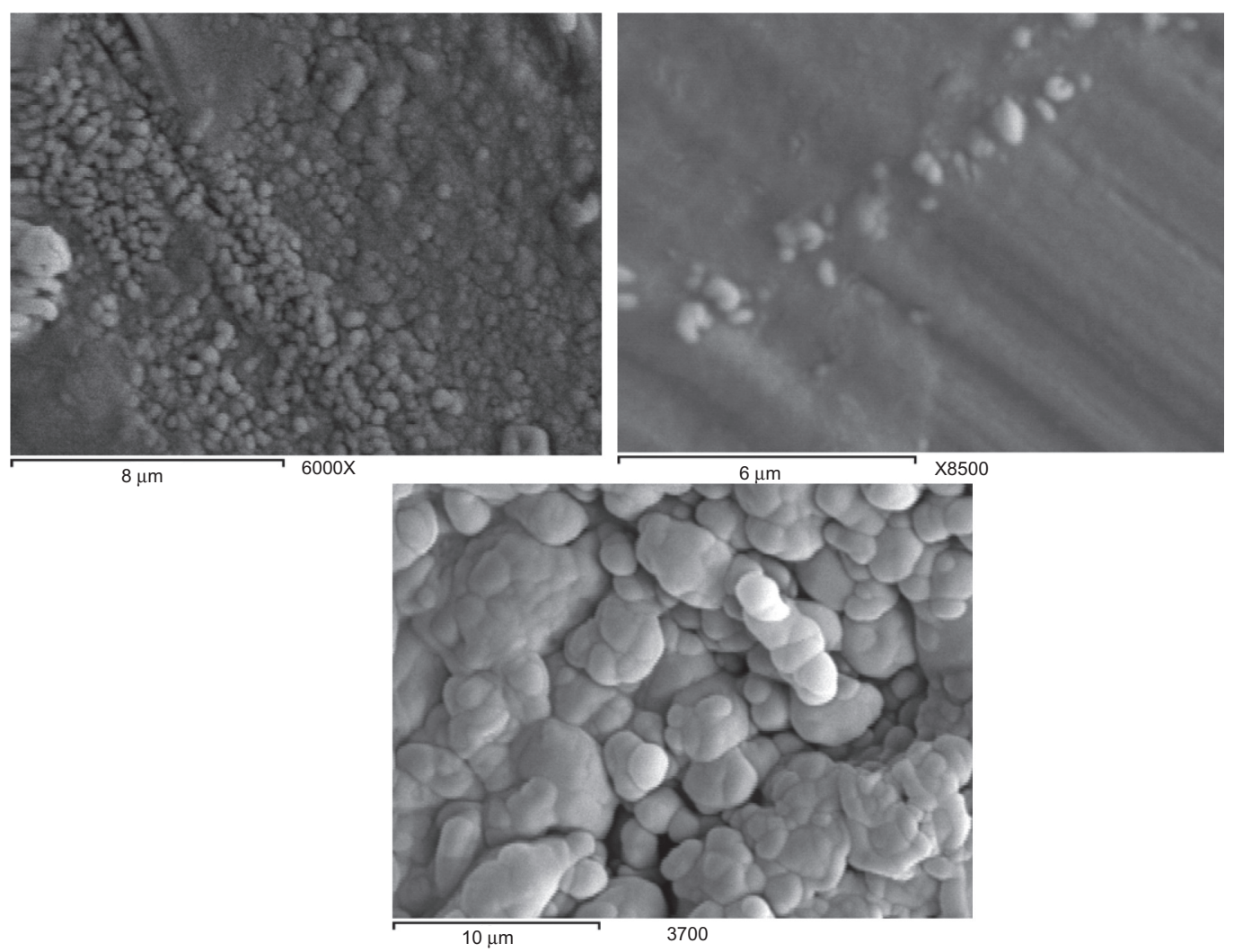

Figure I SEM images for a) the progesterone nanosuspension after lyophilization; b) the progesterone nanosuspension sample before lyophilization; c) the progesterone powder as received. 


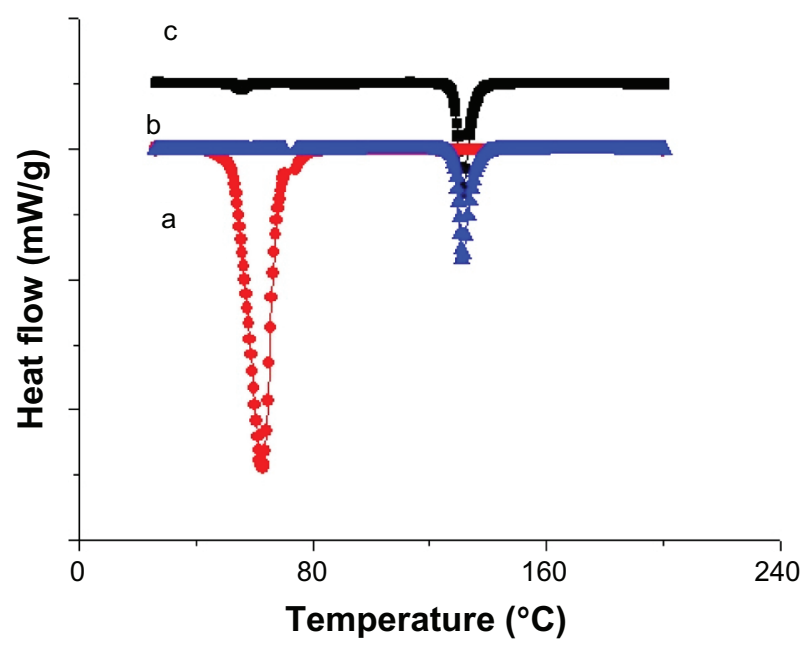

Figure 2 Differential scanning calorimetry thermograms for a) stearic acid; b) progesterone; c) progesterone nanosuspension.

lower than that of the pure drug, which may be attributed to the presence of a small amount of stearic acid surrounding the progesterone without invading it; however, there was no clear evidence supporting this theory. The results showed an absence of a significant shift in the endothermic peak of the progesterone (the peak shifted from $131^{\circ} \mathrm{C}$ to $128^{\circ} \mathrm{C}$ ), which is an indication of the lack of significant changes in the crystalline state of the progesterone and hence it is an indication of the presence of stearic acid on the surface, but not within the progesterone particles. The results of the DSC thermographs are summarized in Table 3.

The in vitro dissolution profile of the three nanoparticle series using progesterone powder as a control is shown in Figure 3a. The cumulative percentage of progesterone released from the nanoparticles formed by the addition of $20 \%, 10 \%$, and $5 \%$ of stearic acid at the end of $10 \mathrm{~h}$ was $88 \pm 5.4,76 \pm 8.2$, and $60 \% \pm 5.3 \%$, respectively. A Higuchi plot (amount of PNS series released versus square root of time) indicated a linear release during the $10 \mathrm{~h}$ of the study (Figure 3b). This indicates that the overall rate of progesterone release was controlled by diffusion of the drug from the nanosuspension. It also shows the importance of the stearic acid concentration in modulating the rate of release. By

Table 3 DSC peak integrations for pure progesterone, pure stearic acid, and progesterone nanosuspension in lyophilized form

\begin{tabular}{lll}
\hline Sample & Peak location $\left({ }^{\circ} \mathbf{C}\right)$ & Enthalpy $(\mathrm{J} / \mathbf{g})$ \\
\hline Progesterone & 131.0 & 58.8 \\
Stearic acid & 60.0 & 387 \\
Nanosuspension & 128.9 & 58 \\
progesterone peak & & \\
Stearic peak & 55.6 & 9.8 \\
\hline
\end{tabular}

Abbreviation: DSC, differential scanning calorimetry.

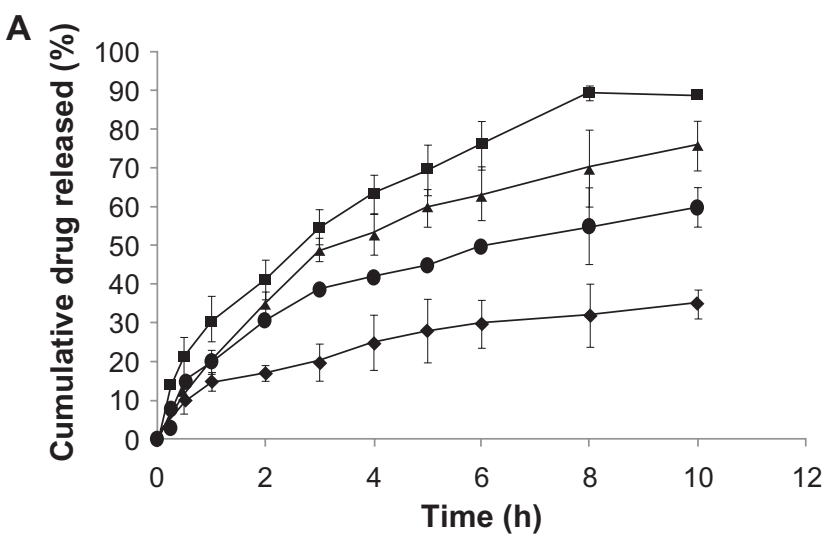

B

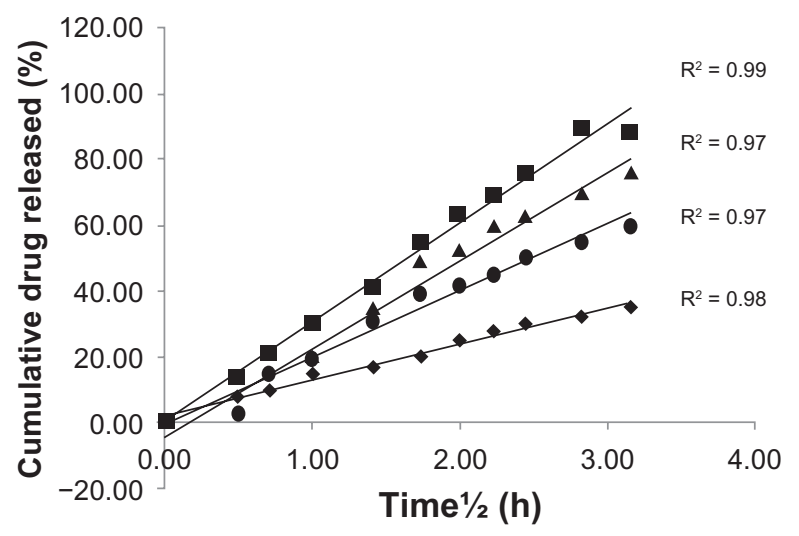

Figure 3 In vitro release of progesterone nanosuspension and progesterone powder. A) cumulative percentage drug release versus time; B) Higuchi plot of the cumulative percentage amount of drug released versus the square root of time.

Notes: progesterone powder suspended in phosphate-buffered saline $(\diamond)$, progesterone nanosuspension stabilized with $5 \%(\mathrm{w} / \mathrm{w})$ stearic acid (O), progesterone nanosuspension stabilized with $10 \%(\mathrm{w} / \mathrm{w})$ stearic acid $(\boldsymbol{\Delta})$, and progesterone nanosuspension stabilized with $20 \%$ (w/w) stearic acid $(\square)$. Each point represents the mean of three replicates. Error bars were omitted in some series for clarity. The in vitro release study was conducted at $25^{\circ} \mathrm{C}$.

increasing the stearic acid concentration, a small amount of nanosuspension of progesterone was formed with low a polydispersity index, which indicates that the size distribution of the particles is homogenous. Therefore, Ostwald ripening is not likely to occur in this case. Ostwald ripening takes place if the particle size distribution is not homogenous or polydisperse. According to this theory, the dissolution pressure over the small particles with an increased degree of curvature of the surface is increased. Therefore, smaller particles dissolve and recrystallize on the surface of larger particles leading to an increase in the particle size and consequently the dissolution rate is decreased due to the formation of large particles. ${ }^{27}$ The rate of dissolution was found to be in the following order: progesterone powder $>$ progesterone with stearic acid $(5 \%)>$ progesterone with stearic acid $(10 \%)>$ progesterone with stearic acid $(20 \%)$. Sink conditions were maintained in this experiment by increasing the surface area of the drug used so the solubility was enhanced. 
The saturated solubility of the nanosuspension containing stearic acid (20\%) was assessed to be $295 \mu \mathrm{g} / \mathrm{mL}$ while the solubility of natural progesterone was $7 \mu \mathrm{g} / \mathrm{mL}$. Stearic acid as an amphiphilic moiety might enhance the solubility of the drug by stabilizing the nanoparticles produced and by the formation of hydrogen bonds with water in the dissolution medium. It is necessary to have sink condition so that the release of drug is solely governed by the delivery system and not affected by the solubility factors. ${ }^{28}$

Therefore, increasing the concentration of stearic acid from $5 \%$ to $20 \%$ enhanced the physicochemical properties by forming smaller particles with a lower polydispersity index and with a zeta potential up to $41 \mathrm{mV}$ (Table 2). The negative value of the zeta potential of the nanosuspensions linearly increased, reaching $41 \mathrm{mV}$ in presence of $20 \%$ stearic acid. This value provided colloidal stability for the nanoparticles. In addition, it gave them a greater ability for distribution within hydrophilic bases. This value is also far from the agglomeration threshold defined by Riddick. ${ }^{29}$

The formula that included stearic acid (20\%) was chosen to complete the study by including the nanosuspension in the pluronic thermosensitive bases. Different blends of pluronic F127 with HPMC and MC as additives were examined to determine which base was best able to elongate the release of the nanoparticles. Incorporation of hydrophilic polymers (HPMC) or the less hydrophilic additive MC into pharmaceutical formulations is common practice for retarding the release of drugs, thereby achieving a sustained drug delivery system. A set of experiments was conducted to choose the base most able to sustain the release of progesterone when administered via the IM route. In order to choose a limited number of bases able to deliver progesterone in a sustained release manner, we needed to know the optimum concentration of polymer blends that was less prone to erosion by the dissolution medium.

The nine bases used in this study existed as a free flowing but viscous liquid at the storage temperature $\left(4^{\circ} \mathrm{C}\right)$. The concentrations of the additives used in this study represent the highest concentration that kept the sol-gel characteristics of the F127 bases (data not shown). The F127 formulations which contained no additive were used as controls.

\section{Characterization of the thermosensitive bases}

\section{Gelling temperature and rheological properties of thermosensitive gels}

Table 4 shows the sol-gel transition temperature of the nine bases in the presence or in the absence of PNS. No significant difference was found between the gelling temperature of most bases either in the presence or in the absence of progesterone nanoparticles. Only B2 showed a significant difference between the gelling temperature of the bases in the presence and in the absence of the drug at $P<0.05$. However, a remarkable decrease in the gelling temperature occurred with the increase in F127 concentrations. The same phenomenon (gelling temperature decrease) was recognized upon the addition either of HPMC or MC to the bases (Table 4).

Pluronics have thermoreversible behavior in aqueous solution. By increasing the temperature, they aggregate in micelles to minimize the free energy of the solution. However, at low temperature, pluronics exist as monomers in solution. Upon warming, the equilibrium between monomers and micelles is reached, and finally aggregates are formed at either higher temperatures or higher concentrations. These micelles are usually spherical in shape and consist

Table 4 Gelling temperature and viscosity of different FI 27 bases either in the presence or in the absence of progesterone ( $n=4 \pm$ SD)

\begin{tabular}{|c|c|c|c|c|c|c|c|}
\hline $\begin{array}{l}\text { Base } \\
\text { No. }\end{array}$ & $\begin{array}{l}\text { Gelling } \\
\text { temperature } \\
\left({ }^{\circ} \mathrm{C}\right)^{\mathrm{a}}\end{array}$ & $\begin{array}{l}\text { Gelling } \\
\text { temperature } \\
\left({ }^{\circ} \mathrm{C}\right)^{\mathrm{b}}\end{array}$ & $t$-test & $\begin{array}{l}\text { Viscosity } \\
(c P)^{c}\end{array}$ & $\mathbf{N}$ & $\begin{array}{l}\text { Viscosity } \\
(\mathrm{cP})^{\mathrm{d}}\end{array}$ & $\mathbf{N}$ \\
\hline $\mathrm{BI}$ & $29.8 \pm 0.44$ & $29.4 \pm 0.54$ & $P>0.05$ & 370 & 2.60 & 410 & 2.40 \\
\hline B2 & $48.75 \pm 0.50$ & $45.25 \pm 0.50$ & $P<0.05$ & 120 & 2.03 & 340 & 1.80 \\
\hline B3 & $25.5 \pm 0.50$ & $25.25 \pm 0.50$ & $P>0.05$ & 420 & 1.72 & 510 & 3.12 \\
\hline B4 & $23.25 \pm 0.5$ & $22.5 \pm 1.9$ & $P>0.05$ & 630 & 2.10 & 1120 & 2.12 \\
\hline B5 & $21 \pm 0.80$ & $20.8 \pm 0.50$ & $P>0.05$ & 430 & 2.43 & 340 & 2.22 \\
\hline B6 & $19 \pm 0.80$ & $19 \pm 0.00$ & $P>0.05$ & 794 & 2.82 & 945 & 3.01 \\
\hline B7 & $15 \pm 0.50$ & $13 \pm 0.00$ & $P>0.05$ & 1958 & 2.51 & 2880 & 3.58 \\
\hline B8 & $13 \pm 0.00$ & $10.25 \pm 0.50$ & $P>0.05$ & 2214 & 2.82 & 2987 & 3.07 \\
\hline B9 & $10.5 \pm 0.50$ & $10 \pm 0.00$ & $P>0.05$ & 2589 & 2.76 & 3306 & 2.1 \\
\hline
\end{tabular}

Notes: $\mathrm{N}$ is a constant that represents the slope of log $\mathrm{F}$ against log $\mathrm{G}$. ${ }^{\mathrm{a}} \mathrm{Gelling}$ temperatures of bases in the absence of progesterone; ${ }^{\mathrm{b}} \mathrm{Gelling}$ temperatures of bases in the presence of progesterone; ' $\mathrm{V}$ iscosity of gel in the absence of progesterone at $4^{\circ} \mathrm{C}$; ${ }^{\circ} \mathrm{Viscosity}$ of gel in the presence of progesterone $4^{\circ} \mathrm{C}$. Abbreviations: $\mathrm{CP}$, centipoises; SD, standard deviation. 
of a hydrophobic core of poly (oxypropylene) blocks and hydrophilic shell of polyethylene glycol. ${ }^{30,31}$

The decrease in the gelation temperature with the increase in F127 concentration may be attributed to the higher number of micelles that occupy the same volume of aqueous medium. When the concentration of F127 increases, the gel structure becomes more packed in a lattice pattern, which may lead to gelling temperature depression. However, the present study shows that PNS in a concentration of $6 \mathrm{mg} / \mathrm{mL}$ does not reduce the gelation temperature of F127 at all concentrations. This phenomenon may be attributed to the hydrophobic nature of progesterone. Progesterone nanoparticles might be localized within the micelles core so they did not affect water content of the gel, micellar aggregation, or the gelling temperature. ${ }^{32}$ It is clear that all the bases except B2 will be able to congeal inside the body at physiological temperature. In most of the studied bases, the gelation temperature is far below the body temperature. This difference is a sign for the in situ congealing of the gel within the body. If the difference between gelling point of the gel and physiological temperature is small, the in situ congealing of the gel cannot be assured and a burst in the drug release may occur. The drug can diffuse out of the nonsolidified gel more rapidly and the burst can occur. ${ }^{33}$

Table 4 shows the values of the viscosity coefficient of the nine bases at $4{ }^{\circ} \mathrm{C}$ as well. The flow behavior of the different gel bases was studied according to equation (2):

$$
\log G=N \log F-\log \eta
$$

where $F$ is the shear rate in $\sec ^{-1} ; G$ is the shear stress in dyne $/ \mathrm{cm}^{2}, \eta$ is the viscosity coefficient in $\mathrm{cP}$ and calculated from the intercept of $\log \mathrm{F}$ against $\log \mathrm{G}$, while $\mathrm{N}$ is the slope of the plot. When $\mathrm{N}$ is less than 1, dilatant flow is attained, and if it is greater than 1 , pseudoplastic flow is achieved. ${ }^{34}$

F127 bases can be administered in liquid form at $4^{\circ} \mathrm{C} . .^{34-36}$ When converted to semisolid gels at body temperature, they act as sustained release depots (1). All of the investigated bases show a sheer thinning behavior and pseudoplastic flow which can be determined from the slope of the plot above $1 .{ }^{34}$ The viscosity coefficient is usually increased by increasing the concentration of pluronics. Addition of progesterone nanoparticles did not affect the trend of the gel flow, ie, pseudoplasticity. The viscosity is a very important parameter because it has a direct relationship with syringeability. In development of thermosensitive injectable gels, the syringe-ability is an important factor, influencing the ease of administration of the injectable gels to the body. The threshold of appropriate syringe-ability was reported by
Xuan et al. ${ }^{37}$ Below this threshold, it is easy to administer the gel. For the gels containing poloxamer, the threshold in syringe-ability is a viscosity of about $300 \mathrm{mPa}$.s which is equivalent to $300 \mathrm{cP} \cdot{ }^{37}$ In the present study not all the bases are below this threshold; however they do undergo a sheer thinning behavior when they are shaken in the bottle or during injection by syringes.

\section{The cumulative percentage weight of dissolved gel (matrix erosion or weight loss)}

The cumulative percentage weight of dissolved gel experiment (matrix erosion/weight lost) was carried out to study the correlation between the cumulative percentage weight loss of dissolved gel versus time (Figures $4 \mathrm{a}, 4 \mathrm{~b}, 4 \mathrm{c}$ ). The bases, which show high viscosity and rigidity at $37^{\circ} \mathrm{C}$, are less prone to erosion and to weight loss than the less viscous ones. ${ }^{22}$ Therefore, all of the bases with a pluronic gel concentration of $17 \% \mathrm{w} / \mathrm{v}$ such as B1, B2, and B3 (Figure 4a) dissolved faster than the others, which have higher concentration of pluronic, ie, B4, B5, B6, B7, B8, and B9 (Figure 4b and 4c).

$\mathrm{B} 1$ dissolved after $6 \mathrm{~h}$ while $\mathrm{B} 3$ dissolved after $8 \mathrm{~h}$. However, B2 (the base which contained 17\% pluronic gel and HPMC) did not show any tendency to congeal at $37^{\circ} \mathrm{C}$. This may be due to the presence of a fewer number of micelles per unit volume in $\mathrm{B} 2$, in addition to the extensive hydrating effect of HPMC in this base..$^{22,30}$ This combined effect might be the main reason why the gel of B2 did not solidify under the conditions of the experiment.

In all of the studied bases, the cumulative amounts of gel dissolved versus time were in the order of pluronic $>$ pluronic and HPMC $>$ pluronic and MC, and there was a strong correlation with time $\left(r^{2}>0.97\right)$. Addition of $M C$ to the bases showed a linear correlation between the weight loss of the base versus different time intervals. This phenomenon may be attributed to the chemical structure of MC which is less hydrophilic than both pluronic and HPMC. Hydrophilic bases tend to keep water in their micellar aqueous channels which may lead to the increase in the percentage of gel dissolved versus time. Four bases that exhibited slower gel dissolutions were selected for further in vitro release studies with $25 \%$ pluronic gel $\mathrm{w} / \mathrm{v}$ as a control.

\section{The cumulative release of the drug}

\section{from the thermosensitive matrix}

The effect of the pluronic gel concentration on the PNS release kinetics from four bases, namely B4, B5, B6, B8, and $\mathrm{B} 9$, were investigated. The in vitro dissolution profile of the PNS in gels is shown in Figure 5. It is clear from this 

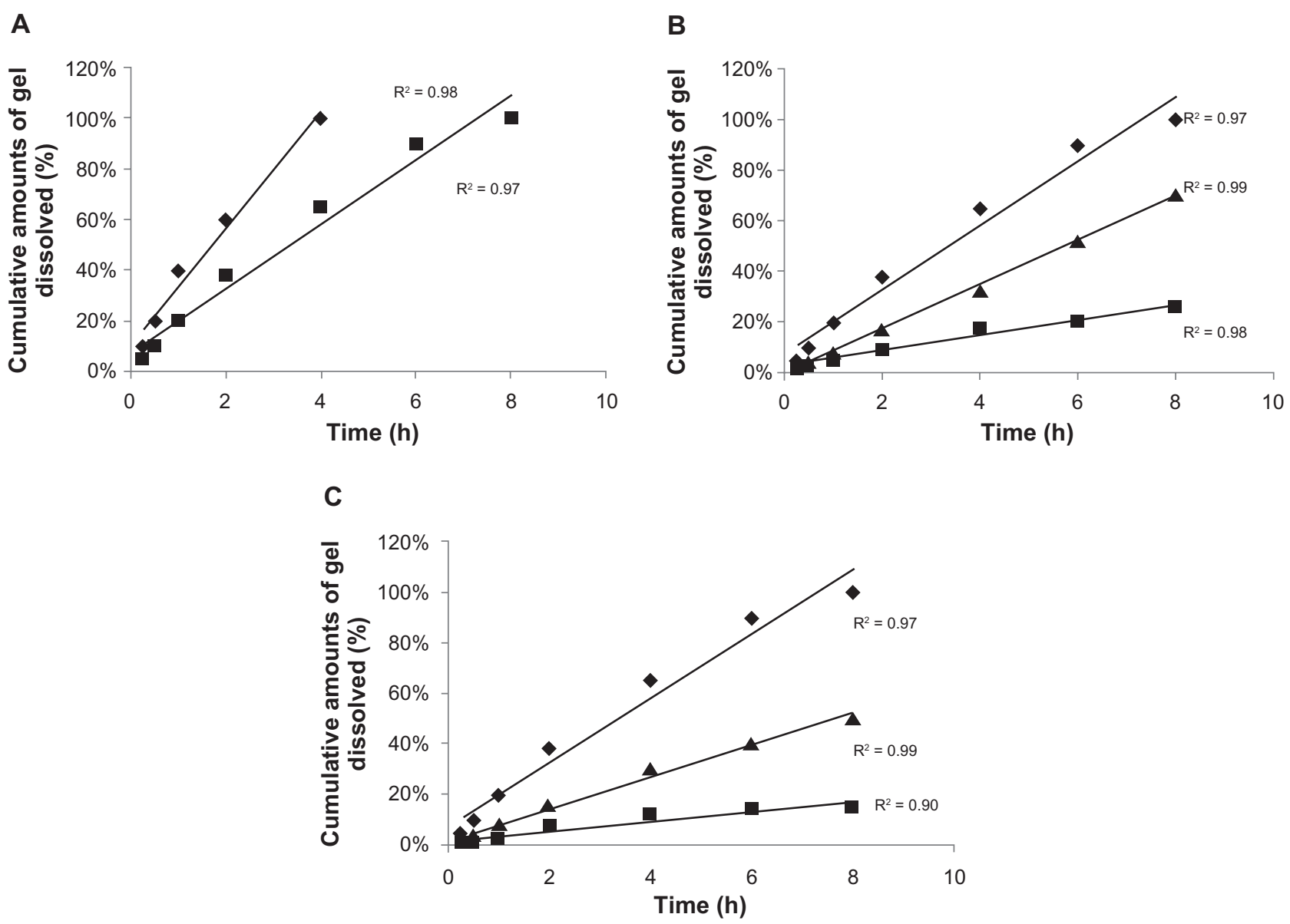

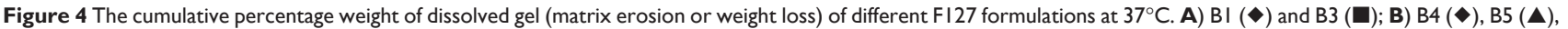

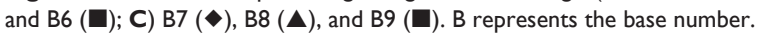

figure that the addition of $\mathrm{MC}$ was able to retard the release of progesterone after $10 \mathrm{~h}$. B6 and B9 that contained pluronic F127 (25\% and 30\% w/v) plus MC released only $44 \%$ and $40 \%$ of the added PNS, respectively, while B5 and B8 gel contained pluronic F127 (25\% and 30\% w/v) plus HPMC

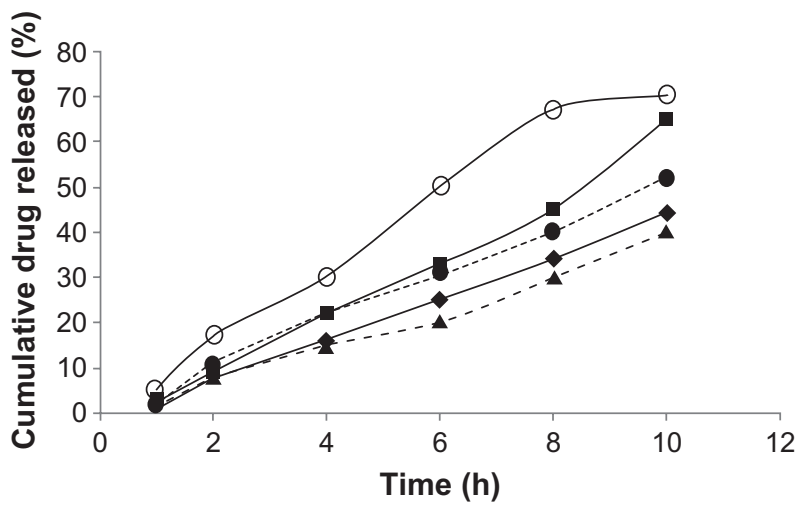

Figure 5 Cumulative drug release (\%) versus time at $37^{\circ} \mathrm{C}$ for pluronic $25 \%(\mathrm{O})$, pluronic $25 \%$ and $1 \%$ HPMC (ם), pluronic $30 \%$ and $1 \%$ HPMC (O), pluronic $25 \%$ and I\% MC ( $)$, and pluronic 30\% and I\% MC $(\boldsymbol{\Delta})$. Each point represents the mean of three replicates. Error bars were omitted for clarity. released only $65 \%$ and $55 \%$ of the added PNS, respectively. The release kinetics of the drug from the four series followed a zero order of kinetics. However, the release of the drug from B4 (the $25 \% \mathrm{w} / \mathrm{v}$ pluronic) gel was found to be controlled by diffusion (Figure 5).

There was a high correlation between the percentage weight of dissolved gel with the cumulative percentage drug release in most of the studied series except in B5 which contained the mixture of $25 \%$ pluronic gel and HPMC (Figure 6a and $6 \mathrm{~b})$. This indicates that the overall rate of the drug release into the dissolution medium was controlled by the dissolution of the gel. However, the involvement of other mechanisms, including diffusion of the drug through extramicellar aqueous channels, degradation of the gel matrix, or diffusion out of the nanosuspended particles, cannot be excluded..$^{21,22,30}$ The $25 \%$ pluronic gel with the MC base (B6) was shown to have the highest correlation between cumulative drug release with percentage weight of dissolved gel $\left(\mathrm{r}^{2}>0.99\right)$. In addition to this, this gel showed a very slow dissolution rate versus time, therefore it was chosen to carry out the in vivo study. 


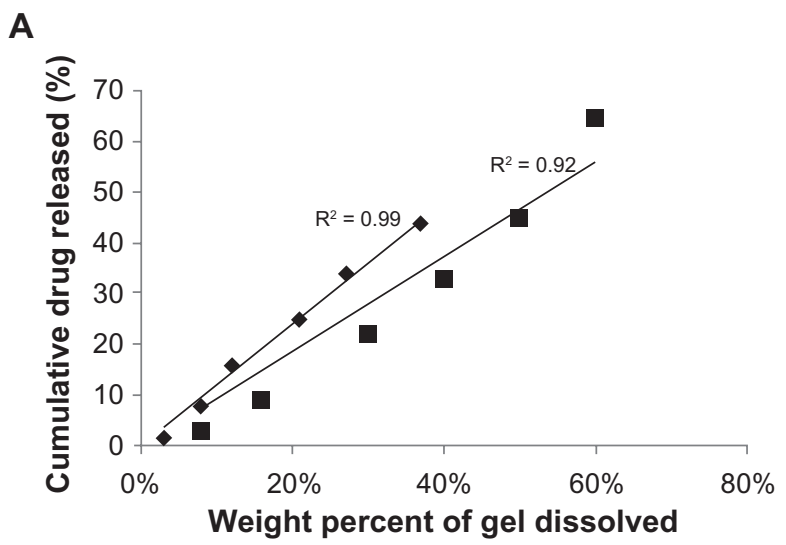

B

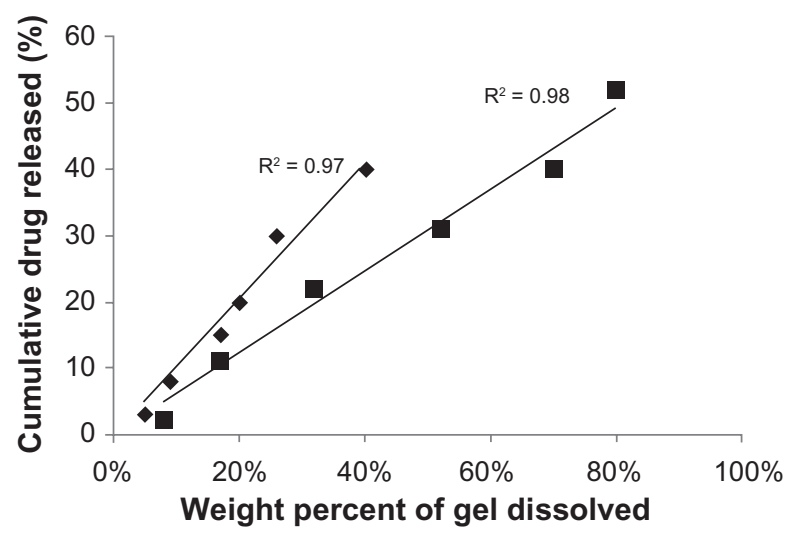

Figure 6 The correlation between the cumulative amount of dissolved gel (percentage weight of pluronic FI27 dissolved alone or with hydrophilic additives) and the cumulative percentage weight of drug released during the first $8 \mathrm{~h}$ at $37^{\circ} \mathrm{C}$. A) The concentration of pluronic is $25 \%$; B) The concentration of pluronic is $30 \%$. $(\diamond)$ for MC, ( $\mathbf{\square})$ for HPMC additives.

\section{In vivo study}

In Figure 7, the pharmacokinetic parameters of the PNS $(6 \mathrm{mg} / \mathrm{mL})$ in pluronic F127and MC gel (B6) were evaluated in comparison to the control progesterone suspension. The results are presented as means \pm standard deviation and were subjected to non compartmental analysis using WinNonlin software (version 1.5; Pharsight Corporation, St Louis, MO). After injection of PNS into the rats, the maximum serum concentration $\left(\mathrm{C}_{\max }\right)$ of $22.1 \pm 1.9 \mathrm{ng} / \mathrm{mL}$ was reached at a $\mathrm{T}_{\text {max }}$ of $4.05 \pm 0.1 \mathrm{~h}$. The terminal half-life was $12.7 \pm 0.8 \mathrm{~h}$. A higher progesterone plasma concentration of $37.5 \pm 11.8 \mathrm{ng} / \mathrm{mL}$ was achieved more rapidly with the progesterone suspension in PBS since it was reached at a $T_{\max }$ of $0.75 \pm 0.0 .28 \mathrm{~h}$. The terminal half-life of the test formula was $12.7 \pm 0.8 \mathrm{~h}$, while it was $7.67 \pm 3.5 \mathrm{~h}$ for the control. The $\mathrm{AUC}_{0-\infty}$ of the test formula was $452.75 \pm 42.8 \mathrm{ng} \cdot \mathrm{h} / \mathrm{mL}$ and the total mean residence time (MRT) was $18.57 \pm 1.44 \mathrm{~h}$. On the other hand, the $\mathrm{AUC}_{0-\infty}$ of the control was $206.7 \pm 21.9$ and the total MRT was $10.2 \pm 1.7 \mathrm{~h}$. Applying $t$-test for non paired data, the results of PNS were significantly different at $P<0.001$.

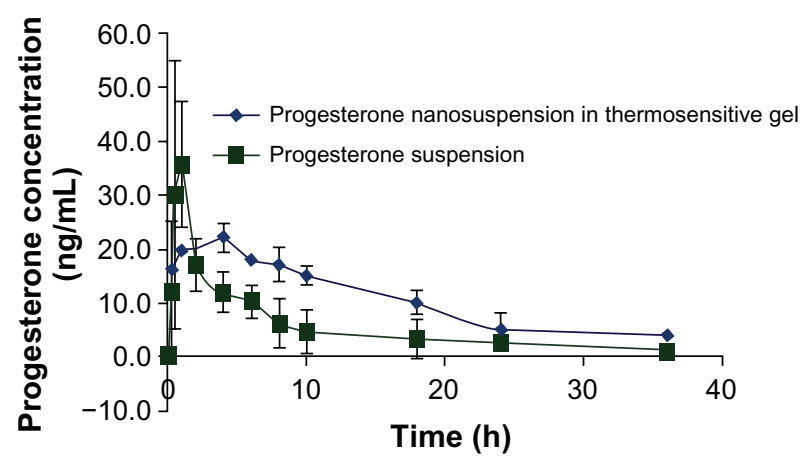

Figure 7 Pharmacokinetic profile of progesterone nanosuspension in FI27 (25\% $\mathrm{w} / \mathrm{v})$ with $\mathrm{MC}(\mathrm{I} \% \mathrm{w} / \mathrm{v})(\diamond)$ and progesterone powder in PBS $(\boldsymbol{\square})$ in ovariectomized female rats.

The previous results showing that poloxamer vehicle resulted in prolongation of plasma concentrations of PNS, which was detected from the ratio between the MRT of the test formula to the MRT of the control, was found to be equal to 1.8. The $\mathrm{T}_{\max }$ for progesterone in pluronic test base carrying PNS (test) was four times slower than that of the control. In the case of PNS embedded into the thermosensitive base, a more uniform plasma profile was detected (Figure 7). This effect may be a result of the uniform distribution of PNS in the hydrophilic matrix. At the same time, a slower elimination rate may have had an additional effect in prolonging the effect of the pluronic base. ${ }^{22}$ The relative bioavailability of the test formula to the control was almost $210 \%$, which was found to be significant at $P<(0.001)$.

It is clear from the results that the pluronic gel was successful in modulating the release of progesterone in plasma since it was able to sustain the progesterone level over $36 \mathrm{~h}$ to achieve its therapeutic effect. There was a limited fluctuation in progesterone levels in the blood when the pluronic gel was used which could be predicted from the very narrow standard deviation. This can give an additional advantage for using the gel over using the control.

The therapeutically effective concentration of progesterone was reported to be $2-5 \mathrm{ng} / \mathrm{mL}$ in plasma of some animals. ${ }^{26,38}$ In this work, the lowest level of exogenous progesterone is approaching $5 \mathrm{ng} / \mathrm{ml}$. This level is in agreement with what was reported in the literature about the pharmacokinetics of progesterone. Mannino et al, reported about a subcutaneous implant that contained $40 \mathrm{mg}$ of progesterone in ovariectomized rats. ${ }^{39}$ The peak serum progesterone was $21 \pm 1.6 \mathrm{ng} / \mathrm{mL}$ and the lowest serum level was $6.9 \pm 0.6 \mathrm{ng} / \mathrm{mL}$. In the present study, we formulated PNS in F127 gel using only $6 \mathrm{mg}$ of progesterone and achieved the same level, but for a shorter duration. It is clear that the gel offers advantages of injectability unlike the implants, which require surgical operations. The gel is 
injectable at $4^{\circ} \mathrm{C}$ and has a shear thinning pseudoplastic flow, which facilitates its administration to patients. ${ }^{37}$ Achieving physiological levels of progesterone is a vital requirement to prevent any embryonic loss in oocyte retrieval operations. ${ }^{40}$ Administration of supranormal levels of progesterone during early pregnancy caused reduction in the number of implantation and an increase in the preimplantation loss in mice. ${ }^{41}$ Therefore, achieving low level of progesterone such as the level achieved by the present work, it could be advantageous in bringing the normal progesterone level and keeping the embryo safe.

However, the optimum dose required from progesterone cannot be determined because it depends on the initial level of endogenous progesterone and the level needed to keep the pregnancy. There are inconsistencies in the studies describing the required levels of progesterone for maintaining the pregnancy. In a study reported by Pepe and Rothchild, who measured the level of progesterone in pseudopregnant rats, found progesterone level to be $70 \mathrm{ng} / \mathrm{mL}$ on day five of pregnancy and reaching $120 \mathrm{ng} / \mathrm{mL}$ on day $11 .^{42}$ The same group found that pregnancy can be maintained at level of progesterone $75 \%-80 \%$ lower than the normal value. ${ }^{43}$

In humans, pregnancy outcomes can be predicted from serum progesterone levels which ranged from $12.3-80.9 \mathrm{ng} / \mathrm{mL}$ for pregnant women and from $8.4-18.2 \mathrm{ng} / \mathrm{mL}$ in non pregnant women. ${ }^{44}$ Keeping a steady level of progesterone during early pregnancy is indicated. The present formula offers delivery of progesterone for an extended period of time to be given every $36 \mathrm{~h}$ instead of every $24 \mathrm{~h}$. Progesterone in the present formula is suspended in hydrophilic base which may provide a more convenient alternative than oil bases provided in market. This may offer a new application of our formula in future. However, a higher concentration of PNS may be needed to provide a higher input of progesterone in plasma. ${ }^{45}$

\section{Acknowledgment}

The author thanks Dr Sahar K Amin and Dr Gehan A El-Menofy for their valuable help in ovariectomizing the rats and during the pharmacokinetic study.

\section{Disclosure}

The author report no conflicts of interest in this work.

\section{References}

1. Fahraeus L, Larsson-Cohn U, Wallentin L. L-norgestrel and progesterone have different influences on plasma lipoproteins. Eur J Clin Invest. 1983;13(6):447-453.

2. Ottoson UB, Carlstrom K, Damber JE, von Schoultz B. Serum levels of progesterone and some of its metabolites including deoxycorticosterone after oral and parenteral administration. Br J Obstet Gynaecol. 1984;91(11):1111-1119.
3. Knopp RH. Cardiovascular effects of endogenous and exogenous sex hormones over a woman's lifetime. Am J Obstet Gynecol. 1988;158 (6 Pt 2):1630-1643.

4. Jiang CW, Sarrel PM, Lindsay DC, Poole-Wilson PA, Collins P. Progesterone induces endothelium-independent relaxation of rabbit coronary artery in vitro. Eur J Pharmacol. 1992;211(2):163-167.

5. Nillius SJ, Johansson ED. Plasma levels of progesterone after vaginal, rectal, or intramuscular administration of progesterone. Am J Obstet Gynecol. 1971;110(4):470-477.

6. Tavaniotou A, Smitz J, Bourgain C, Devroey P. Comparison between different routes of progesterone administration as luteal phase support in infertility treatments. Hum Reprod Update. 2000;6(2):139-148.

7. Roman E, Aytoz A, Smitz JE, et al. Analysis of the bleeding pattern in assisted reproduction cycles with luteal phase supplementation using vaginal micronized progesterone. Hum Reprod. 2000;15(7):1435-1439.

8. Chen X, Young TJ, Sarkari M, Williams RO 3rd, Johnston KP. Preparation of cyclosporine A nanoparticles by evaporative precipitation into aqueous solution. Int J Pharm. 2002;242(1-2):3-14.

9. Zili Z, Sfar S, Fessi H. Preparation and characterization of poly-epsiloncaprolactone nanoparticles containing griseofulvin. Int J Pharm. 2005;294(1-2):261-267.

10. Zhang X, Xia Q, Gu N. Preparation of All-Trans Retinoic Acid nanosuspensions using a modified precipitation method. Drug Dev Ind Pharm. 2006;32(7):857-863.

11. van Eerdenbrugh B, van den Mooter G, Augustijns P. Top-down production of drug nanocrystals: nanosuspension stabilization, miniaturization and transformation into solid products. Int J Pharm. 2008;364(1):64-75.

12. Kayser O, Olbrich C, Yardley V, Kiderlen AF, Croft SL. Formulation of amphotericin $\mathrm{B}$ as nanosuspension for oral administration. Int J Pharm. 2003;254(1):73-75.

13. Jacobs C, Muller RH. Production and characterization of a budesonide nanosuspension for pulmonary administration. Pharm Res. 2002;19(2):189-194.

14. Peters K, Leitzke S, Diederichs JE, et al. Preparation of a clofazimine nanosuspension for intravenous use and evaluation of its therapeutic efficacy in murine Mycobacterium avium infection. J Antimicrob Chemother. 2000;45(1):77-83.

15. Kassem MA, Abdel Rahman AA, Ghorab MM, Ahmed MB, Khalil RM. Nanosuspension as an ophthalmic delivery system for certain glucocorticoid drugs. Int J Pharm. 2007;340(1-2):126-133.

16. Trotta M, Gallarate M, Pattarino F, Morel S. Emulsions containing partially water-miscible solvents for the preparation of drug nanosuspensions. J Control Release. 2001;76(1-2):119-128.

17. Hecq J, Deleers M, Fanara D, Vranckx H, Amighi K. Preparation and characterization of nanocrystals for solubility and dissolution rate enhancement of nifedipine. Int J Pharm. 2005;299(1-2):167-177.

18. Plumley C, Gorman EM, El-Gendy N, Bybee CR, Munson EJ, Berkland C. Nifedipine nanoparticle agglomeration as a dry powder aerosol formulation strategy. Int J Pharm. 2009;369(1-2):136-143.

19. Johnston TP, Punjabi MA, Froelich CJ. Sustained delivery of interleukin-2 from a poloxamer 407 gel matrix following intraperitoneal injection in mice. Pharm Res. 1992;9(3):425-434.

20. Katakam M, Bell LN, Banga AK. Effect of surfactants on the physical stability of recombinant human growth hormone. J Pharm Sci. 1995;84(6):713-716.

21. Wenzel JG, Balaji KS, Koushik K, et al. Pluronic F127 gel formulations of deslorelin and $\mathrm{GnRH}$ reduce drug degradation and sustain drug release and effect in cattle. $J$ Control Release. 2002;85(1-3):51-59.

22. Bhardwaj R, Blanchard J. Controlled-release delivery system for the alpha-MSH analog melanotan-I using poloxamer 407. J Pharm Sci. 1996;85(9):915-919.

23. Flores A, Gallegos AI, Velasco J, et al. The acute effects of bilateral ovariectomy or adrenalectomy on progesterone, testosterone, and estradiol serum levels depend on the surgical approach and the day of the estrous cycle when they are performed. Reprod Biol Endocrinol. 2008;6:48. 
24. Paget GE, Barnes JM. Toxicity tests. In: Lautrance DR, Bacharach AL, editors. Evaluation of Drug Activities and Pharmacometrics. New York, NY: Academic Press; 1964:135-166.

25. Beck LR, Cowsar DR, Lewis DH, et al. A new long-acting injectable microcapsule system for the administration of progesterone. Fertil Steril. 1979;31(5):545-551.

26. Jameela SR, Kumary TV, Lal AV, Jayakrishnan A. Progesterone-loaded chitosan microspheres: a long acting biodegradable controlled delivery system. J Control Release. 1998;52(1-2):17-24.

27. Wissing SA, Muller RH. Solid lipid nanoparticles as carrier for sunscreens: in vitro release and in vivo skin penetration. J Control Release. 2002;81(3):225-233.

28. Chien Y. Novel Drug Delivery Systems. 29th ed. New York, NY: Informa Healthcare; 1992.

29. Riddick TM. Control of Colloid Stability through Zeta Potential: With a Closing Chapter on its Relationship to Cardiovascular Disease. Philadelphia, PA: Livingston Publishing Company; 1968.

30. Attwood D, Collett JH, Tait CJ. The micellar properties of the poly (oxyethylene)-poly (oxypropylene) copolymer pluronic F127 in water and electrolyte solution. Int J Pharm. 1985;26(1-2):25-33.

31. Gou M, Li X, Dai M, et al. A novel injectable local hydrophobic drug delivery system: biodegradable nanoparticles in thermo-sensitive hydrogel. Int J Pharm. 2008;9(1-2):228-233.

32. Pisal SS, Paradkar AR, Mahadik KR, Kadam SS. Pluronic gels for nasal delivery of Vitamin B12. Part I: preformulation study. Int J Pharm. 2004;270(1-2):37-45.

33. Hatefi A, Amsden B. Biodegradable injectable in situ forming drug delivery systems. J Control Release. 2002;80(1-3):9-28.

34. El Laithy HM, El-Shaboury KM. The development of Cutina lipogels and gel microemulsion for topical administration of fluconazole. AAPS PharmSciTech. 2002;3(4):E35.

35. Johnston TP, Punjabi MA, Froelich CJ. Sustained delivery of interleukin-2 from a poloxamer 407 gel matrix following intraperitoneal injection in mice. Pharm Res. 1992;9(3):425-434.

36. Sonoda A, Nitta N, Ohta S, et al. Controlled release and antitumor effect of pluronic F127 mixed with cisplatin in a rabbit model. Cardiovasc Intervent Radiol. 2010;33(1):135-142.
37. Xuan JJ, Balakrishnan $\mathrm{P}, \mathrm{Oh} \mathrm{DH}$, et al. Rheological characterization and in vivo evaluation of thermosensitive poloxamer-based hydrogel for intramuscular injection of piroxicam. Int J Pharm. 2010; 395(1-2):317-323.

38. Deluca PP, Mehta RC, Hausberger AG, Thanoo BC. Biodegradable polyesters for drug and polypeptide delivery. In: El Nokaly MA, Piatt DM, Carpentier BA, editors. Polymeric Delivery Systems: Properties and Applications. Washington, DC: ACS Symposium Series American Chemical Society; 1993:53-79.

39. Mannino CA, South SM, Inturrisi CE, Quinones-Jenab V. Pharmacokinetics and effects of 17 beta-estradiol and progesterone implants in ovariectomized rats. J Pain. 2005;6(12):809-816.

40. Arkaravichien W, Kendle KE. Critical progesterone requirement for maintenance of pregnancy in ovariectomized rats. J Reprod Fertil. 1990;90(1):63-70.

41. Harini C, Sainath SB, Reddy PS. Progesterone administration induces preimplantation embryonic loss in mice. Fertil Steril. 2009; 91(5 Suppl):2137-2141.

42. Pepe GJ, Rothchild I. A comparative study of serum progesterone levels in pregnancy and in various types of pseudopregnancy in the rat. Endocrinology. 1974;95(1):275-279.

43. Pepe GJ, Rothchild I. Serum progesterone levels in ovariectomized rats injected with progesterone and estrone: relation to pregnancy maintenance and growth of decidual tissue. Endocrinology 1973;93(5): 1193-1199.

44. Young E Jr, Domenech L, Ponte L, Quintana R, van Thillo G, Young G. P-570: pregnancy outcome after ART may be predicted by serum progesterone levels on the day of [beta] hCG testing. Fertil Steril. 2006;86(3):S346.

45. Feltenstein MW, See RE. Plasma progesterone levels and cocaineseeking in freely cycling female rats across the estrous cycle. Drug Alcohol Depend. 2007;89(2-3):183-189.
International Journal of Nanomedicine

\section{Publish your work in this journal}

The International Journal of Nanomedicine is an international, peerreviewed journal focusing on the application of nanotechnology in diagnostics, therapeutics, and drug delivery systems throughout the biomedical field. This journal is indexed on PubMed Central, MedLine, CAS, SciSearch ${ }^{\circledR}$, Current Contents ${ }^{\circledR} /$ Clinical Medicine,

\section{Dovepress}

Journal Citation Reports/Science Edition, EMBase, Scopus and the Elsevier Bibliographic databases. The manuscript management system is completely online and includes a very quick and fair peer-review system, which is all easy to use. Visit http://www.dovepress.com/ testimonials.php to read real quotes from published authors. 